\title{
Hippocampal Sclerosis in the Oldest Old: A Finnish Population-Based Study
}

\author{
Mia Kero $^{\mathrm{a}}$, Anna Raunio ${ }^{\mathrm{a}}$, Tuomo Polvikoski ${ }^{\mathrm{b}}$, Pentti J. Tienari ${ }^{\mathrm{c}}$, Anders Paetau $^{\mathrm{a}, 1}$ \\ and Liisa Myllykangas ${ }^{\mathrm{a}, 1, *}$ \\ ${ }^{a}$ Department of Pathology, University of Helsinki and HUSLAB, Helsinki University Hospital, Helsinki, Finland \\ ${ }^{\mathrm{b}}$ Institute of Neuroscience, University of Newcastle, Newcastle upon Tyne, United Kingdom \\ ${ }^{\mathrm{c}}$ Department of Neurology, University of Helsinki and Helsinki University Hospital, Helsinki, Finland
}

Handling Associate Editor: Irina Alafuzoff

Accepted 31 January 2018

\begin{abstract}
.
Background: There are only few population-based studies that have systemically investigated the prevalence of hippocampal sclerosis (HS) in the very old. The frequency of unilateral versus bilateral HS has been rarely studied.

Objective: We investigated the prevalence and laterality of HS and its association with other neurodegenerative and vascular pathologies in a population-based sample of very elderly. Furthermore, the concomitant presence of immunoreactivity for TDP-43, p62, and HPtau was studied.

Methods: The population-based Vantaa 85+ study includes all inhabitants of the city of Vantaa, who were $>85$ years in 1991 $(n=601)$. Neuropathological assessment was possible in 302 subjects. Severity of neuronal loss of CA sectors and subiculum was determined bilaterally by HE- staining. Immunohistochemistry performed using antibodies for TDP-43, p62, and HPtau. Results: Neuronal loss and pathological changes in the hippocampus sector CA1 and subiculum were observed in 47 of the 302 individuals (16\%), and $51 \%$ of these changes were bilateral. HS without comorbid neurodegenerative pathology was found in $1 / 47$ subjects with HS $(2 \%)$. Dementia $(p<0.001)$ and TDP-43 immunopositivity of the granular cell layer of the dentate fascia $(p<0.001)$ were strongly associated with HS. The CERAD score, immunopositivity for HPtau and p62 in the granular cell layer of the fascia dentate were also associated.

Conclusion: HS is prevalent (16\%) in the oldest old population, but HS without any comorbid neurodegenerative pathology is rare. The high frequency of unilateral HS (49\%) implied that bilateral sampling of hippocampi should be routine practice in neuropathological examination.
\end{abstract}

Keywords: Dementia, hippocampal sclerosis, hippocampal sclerosis without any comorbid neurodegenerative pathology, laterality, population-based, TDP-43, very old

\section{INTRODUCTION}

The term hippocampal sclerosis (HS) [1-11] is commonly used to refer to old age-associated

\footnotetext{
${ }^{1}$ These authors contributed equally to this work.

*Correspondence to: Liisa Myllykangas, MD, PhD, Pathology, University of Helsinki and Helsinki University Hospital, Haartmaninkatu 3C, 00290 Helsinki, Finland. Tel.: +358504482805; Fax: +358 9 47175830; E-mail: liisa.myllykangas@ helsinki.fi.
}

brain disease with neuronal loss and gliosis in the hippocampal formation that is out of proportion to AD-type pathology [12-17] and often associated with TDP-43 (Transactive response binding protein-43) pathology [18-28]. Typical clinical presentation shows cognitive and functional impairment [7, 28-31], and HS can be difficult to distinguish, especially from late-onset Alzheimer's disease (AD) [1, 15, 24, 32-35]. Frequently, HS occurs with other 
age-related neurodegenerative pathologies, and it occurs only rarely without any comorbid pathology [23, 31, 36-40]. Definitions of HS have traditionally varied [20,23], which complicates comparison of HS studies.

The reported prevalence of HS in aged populations is variable, ranging from $2.8 \%$ to over $20 \%$ $[4,6,7,10,11,29,30,34]$. A recent meta-analysis, largely confined to hospital-based materials, reported the oldest old to have a peak in incidence of HS after the age of 95 years [7, 17]. However, there are only few population/community-based studies $[20,30]$ where the prevalence of HS can be reliably investigated. Furthermore, only few studies have systematically investigated whether the loss of neurons appears bilaterally or unilaterally $[11,30]$.

In this study we sought to address the following questions: 1) The prevalence of HS in our unique population based study material (Vantaa 85+ study, all the individuals aged 85 years or over); 2) The frequency of uni- versus bilateral HS; 3) The frequency of HS subjects without any comorbid pathology (absence of apparent other neurodegenerative or vascular disease); 4) The association of HS with other neurodegenerative and vascular pathologies; 5) The associations of TDP-43 and HPtau (hyperphosphorylated)-positive pathology with HS.

\section{MATERIAL AND METHODS}

\section{Subjects and clinical examination}

The Vantaa 85+ study includes all individuals aged $\geq 85$ years, who were living in the city of Vantaa (Southern Finland) as of 1 April $1991(\mathrm{~N}=601)$. Clinical examination was possible in 553 subjects, and autopsies were carried out in 302/553 subjects (55\%). Informed consent for the study was requested from the individuals and/or their close relatives. The approval for the study was admitted by the Ethics Committee of Health Center City of Vantaa. Handling of the health and social work data as well the death certificates was approved by the Finnish Health and Social Ministry. The National Authority for Medico Legal Affairs (VALVIRA) accepted the autopsy tissue sample collection and usage for research purposes. Dementia was diagnosed as part of the clinical examination according to the DSMIIIR criteria. The clinical examinations were performed in 1991, 1994, 1996, 1999, and 2001.

\section{Tissue samples}

Originally, for the previously reported study on $\mathrm{AD}$ [44], hippocampal samples were obtained after at least two weeks formalin-fixation from the right cerebral hemisphere at the level of the lateral geniculate body, and embedded in polyethylene glycol (PEG). Those tissue blocks were re-processed to paraffin for this study. First, a vast majority of PEG matrix was removed manually, after that the blocks were immersed for $2 \mathrm{~min}$ in distilled water. The blocks were kept in neutral buffered formalin $\mathrm{O} / \mathrm{N}$ at room temperature to make sure that PEG was totally removed. Finally, the blocks were processed in tissue processor (Thermo Shandon Excelsior, Thermo Fisher, USA), and embedded into paraffin.

For bilateral assessment of the hippocampal pathology, also the left hippocampus was sampled after several years of formalin-fixation, and embedded in paraffin. The bilateral tissue sections of $6 \mu \mathrm{m}$, stained for standard HE, were used for estimation of general histopathological findings and stage of neuronal loss in each field of the hippocampus. Our standard sampling and assessment protocols to define pathologies related to AD, Lewy body disease, macroscopic brain infarcts and cerebral amyloid angiopathy have been described previously [41-44]. Braak staging of neurofibrillary degeneration was based on Gallyas stained slides as reported before [44]. Assessment of Lewy body pathology was based on immunopositivity of Lewy bodies and neurites ( $\alpha$-synuclein, clone 42 , Transduction Laboratories, USA) as described previously [43]. The assessment of vascular pathology [42] and a standardized neuropathology protocol for neuritic plaque score, CERAD [44], has been reported previously. The diagnosis of capillary amyloid- $\beta$ was determined using Congo red and confirmed by amyloid- $\beta$ immunohistochemistry (amyloid- $\beta$, clone 4G, Senetek PLC, USA) as described earlier [41].

\section{Defining histopathological alterations and laterality}

HS and hemispheric symmetry/asymmetry was determined on HE- staining by estimating the severity of neuronal loss. The density of neurons was assessed semi-quantitatively by three observers MK, LM and AP using a multi-viewer microscope. The criterion for HS was based on discussions of the observers and the earlier publication of Rauramaa et al. [25]. 
The extent of neuronal loss was categorized into three subdivisions.

I. Intact/Infrequent; no sign or minor loss of pyramidal neurons in the CA1 and subiculum

II. Frequent; severe marked loss of pyramidal neurons in the CA1 and subiculum

III. Complete; total loss of pyramidal neurons in the CA1 and subiculum

The subjects fulfilling the criteria for the subdivision I were included in the non-HS group in the statistical analyses.

The subjects fulfilling the criteria for the subdivisions II and III were included in the HS group in the statistical analyses.

\section{Immunohistochemistry}

The right sided hippocampus tissue blocks were cut into $4 \mu \mathrm{m}$ thick sections and stained with the immunostainer LabVision. For the antibodies (p62 [45], TDP-43, and HPtau) we had to use stronger pretreatment conditions, prolonged incubations times and more sensitive detection kits compared to routine samples, due to the high age of the PEG-embedded tissues. The intense pretreatments and staining conditions caused artefactual staining of lipofuscin in some of the samples. However, the intensity and color of lipofuscin pigment (yellowish) was easily separated from the specific immunopositivity (dark brown) (Fig. 1). The polymer- based detection kits were used for detection. All the immunoreactions were visualized using DAB. More detailed information on immunohistochemical stainings is presented

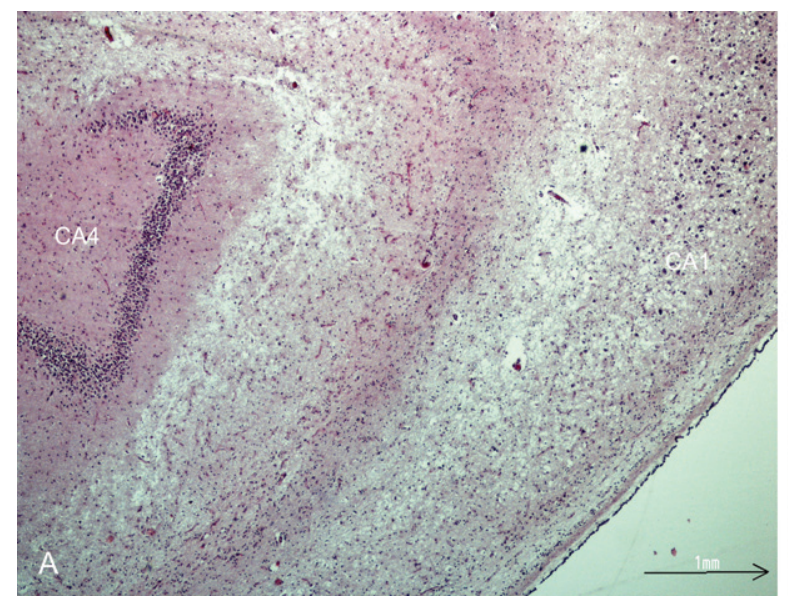

in Table 1. The presence of any specific TDP-43, p62, and HPtau immunopositivity was noted in granular cell layer and in pyramidal cell sectors CA4, CA3, CA2, CA1, and subiculum. The results were ascertained in consensus sessions by three observers (MK, LM, and AP). We used p62- IHC- staining as a confirmatory staining, in order to replicate true neuropathological findings, such as TDP-43 positivity and, on the other hand, to identify other accompanying pathology.

\section{Statistical analyses}

Statistical analyses (Tables 2 and 3) were performed using IBM SPSS Statistics version 22.0. The Chi-Square test was used to compare the differences of sex in individuals with and without HS, and with and without TDP-43 granular cell layer positivity. The Mann-Whitney U test was used to compare age at death in these groups. All the other analyses were performed using binary logistic regression, adjusted for age at death and sex.

\section{RESULTS}

Hippocampi of both hemispheres were analyzed in all subjects of this population-based cohort. 47 of $302(15.6 \%)$ subjects had severe (subdivision II) or complete loss of neurons (subdivision III) of the CA1 sector and subiculum, defined as HS (Table 2). There were 31 subjects in the subdivision II and 16 subjects in the subdivision III. Of those 47 subjects, bilateral changes were observed in $51.1 \%$. Unilateral changes were seen in 23/47 subjects with HS, and unilateral

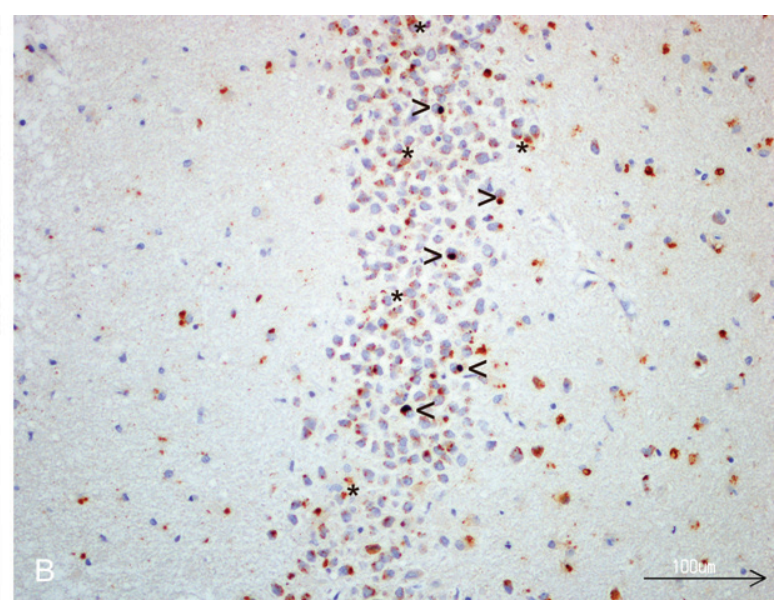

Fig. 1. A) Hippocampal sclerosis, severe neuronal loss in CA1 sector, HE- stained. B) TDP-43 immunostaining of dentate fascia granule cells showing NCIs, (open arrow head), dark brown. Lipofuscin (star) is seen as yellowish granular deposits. 
Table 1

Immunohistochemistry procedures in this study

\begin{tabular}{|c|c|c|c|c|c|}
\hline Antibody & $\begin{array}{l}\text { Clone, Catalog } \\
\text { number, } \\
\text { Manufacturer }\end{array}$ & $\begin{array}{l}\text { Pretreatment } \\
\text { buffer(pH)/Instrument, } \\
\text { Manufacturer }\end{array}$ & $\begin{array}{l}\text { Dilution, Incubation } \\
\text { time } /{ }^{\circ} \mathrm{C}\end{array}$ & $\begin{array}{l}\text { Detection system, } \\
\text { Catalog number, } \\
\text { Manufac- } \\
\text { turer/Incubation } \\
\text { time } /{ }^{\circ} \mathrm{C} \\
\end{array}$ & Staining Instrument \\
\hline TDP-43* & $\begin{array}{l}\text { 11-9, CAC-TIP-PTD- } \\
\text { M01, Cosmobio } \\
\text { Japan }\end{array}$ & $\begin{array}{l}\text { TE-buffer (pH 9.0), } \\
\text { PT-module } \\
\text { (Thermo, Fisher, } \\
\text { Cheshire, UK) }\end{array}$ & $1: 2000,45 \mathrm{~min} / \mathrm{RT}$ & $\begin{array}{l}\text { Envision, K5007, } \\
\text { Agilent, } \\
\text { USA/45 min/RT }\end{array}$ & $\begin{array}{l}\text { LabVision (Thermo } \\
\text { Fisher, Cheshire, } \\
\text { UK) }\end{array}$ \\
\hline PHTau* & $\begin{array}{l}\text { AT8, 90206, } \\
\text { Innogenetics, } \\
\text { Belgium }\end{array}$ & $\begin{array}{l}\text { TE-buffer (pH 9.0) } \\
20 \text { min } / 98^{\circ} \mathrm{C}, \\
\text { PT-module } \\
\text { (Thermo, Fisher, } \\
\text { Cheshire, UK) }\end{array}$ & $1: 800,60 \mathrm{~min} / \mathrm{RT}$ & $\begin{array}{l}\text { Envision Advanced, } \\
\text { K3468, Agilent, } \\
\text { USA/45 min/RT }\end{array}$ & $\begin{array}{l}\text { LabVision (Thermo } \\
\text { Fisher, Cheshire, } \\
\text { UK) }\end{array}$ \\
\hline p62* & $\begin{array}{l}\text { D-3, sc-28359 Santa } \\
\text { Cruz, USA }\end{array}$ & $\begin{array}{l}\text { TE-buffer ( } \mathrm{pH} 9.0) \\
121^{\circ} \mathrm{C} / 10 \mathrm{~min} \\
\text { Autoclaved }\end{array}$ & $1: 50060 \mathrm{~min} / \mathrm{RT}$ & $\begin{array}{l}\text { Envision Advanced, } \\
\text { K3468, Agilent, } \\
\text { USA/30 min/RT for } \\
\text { link ab/30 min/RT } \\
\text { for anti-link ab }\end{array}$ & $\begin{array}{l}\text { LabVision (Thermo } \\
\text { Fisher, Cheshire, } \\
\text { UK) }\end{array}$ \\
\hline
\end{tabular}

${ }^{*}$ General steps for all used antibodies during IHC- staining: 1. Endogenous peroxidase activity was blocked by REAL ${ }^{\mathrm{TM}}$ Peroxidase-Blocking Solution (Dako, S2023, Glostrup, Denmark). 2. Immunoreactions were visualised with DAB (3, 3'-diaminobenzidine tetra- hydrochloride) (Dako, K5007, Agilent, USA). 3. Counterstaining (Mayer's hematoxylin, S330930-2, Agilent, USA) was performed with slide staining instrument SAKURA TISSUE-TEK ${ }^{\circledR}$ PRISMA (Sakura Finetek Europe B.V., The Netherlands).

Table 2

Description of all study subjects, and subjects with and without hippocampal sclerosis. Results of association analyses with different variables

\begin{tabular}{|c|c|c|c|c|}
\hline Variable & All study subjects & $\begin{array}{l}\text { Non-Hippocampal } \\
\text { sclerosis subjects }\end{array}$ & $\begin{array}{c}\text { Hippocampal sclerosis } \\
\text { subjects }\end{array}$ & $p$-value \\
\hline Number of subjects & 302 & 255 & 47 & \\
\hline \multicolumn{5}{|l|}{ Sex } \\
\hline Female/Male & 250 (82.8)/52 (17.2) & 208 (81.6)/47 (18.4) & $42(\mathbf{8 9 . 4}) / 5(\mathbf{1 0 . 6})$ & NS \\
\hline \multicolumn{5}{|l|}{ Age at death } \\
\hline Mean & 92.35 & 92.18 & 93.22 & NS \\
\hline Range & $85.12-105.64$ & $85.52-105.64$ & $85.12-104.77$ & \\
\hline \multicolumn{5}{|l|}{ Dementia status } \\
\hline Demented/non-demented & $195(\mathbf{6 4 . 6}) / 107(\mathbf{3 5 . 4})$ & $150(\mathbf{5 8 . 8}) / 105$ (41.2) & $45(\mathbf{9 5 . 7}) / 2(\mathbf{4 . 3})$ & $<0.001^{*}$ \\
\hline Demented: Female/Male & $165(\mathbf{8 4 . 6}) / 30(\mathbf{1 5 . 4})$ & $124(\mathbf{8 2 . 7}) / 26(\mathbf{1 7 . 3})$ & $41(\mathbf{9 1 . 1}) / 4(8.9)$ & NS \\
\hline CERAD $^{\mathrm{i}}$ & & & & $0.01<p \leq \mathbf{0 . 0 5}^{* *}$ \\
\hline None & $71(\mathbf{2 3 . 5})$ & $65(25.5)$ & $6(\mathbf{1 2 . 8})$ & \\
\hline Sparse & $33(\mathbf{1 0 . 9})$ & 27 (10.6) & $6(\mathbf{1 2 . 8})$ & \\
\hline Moderate & $160(\mathbf{5 3 . 0})$ & $136(\mathbf{5 3 . 3})$ & $24(51.1)$ & \\
\hline Frequent & $38(\mathbf{1 2 . 6})$ & $27(\mathbf{1 0 . 6})$ & $11(\mathbf{2 3 . 4})$ & \\
\hline BRAAK $^{\text {ii }}$ & & & & NS \\
\hline 0 -II & 89 (29.5) & $73(28.7)$ & $16(34.0)$ & \\
\hline III-IV & $141(46.7)$ & $125(49.0)$ & $16(34.0)$ & \\
\hline V-VI & $72(\mathbf{2 3 . 9})$ & $57(\mathbf{2 2 . 6})$ & 15 (31.9) & \\
\hline$\alpha$ - synuclein ${ }^{\mathrm{iii}}$ & & & & NS \\
\hline None & $193(\mathbf{6 3 . 9})$ & $165(64.7)$ & $28(\mathbf{5 9 . 6})$ & \\
\hline Brain Stem & $8(\mathbf{2 . 6})$ & $5(\mathbf{2 . 0})$ & $3(6.4)$ & \\
\hline Limbic & $54(\mathbf{1 7 . 9})$ & 48 (18.8) & $6(12.8)$ & \\
\hline Neocortical & 47 (15.6) & $37(\mathbf{1 4 . 5})$ & $10(\mathbf{2 1 . 3})$ & \\
\hline \multicolumn{5}{|l|}{ Infarct (location) } \\
\hline Any & $162(\mathbf{5 3 . 6})$ & $132(\mathbf{5 1 . 8})$ & $30(\mathbf{6 3 . 8})$ & NS \\
\hline Heart & 119 (41.2) & $95(38.8)$ & $24(\mathbf{5 4 . 5})$ & $\mathbf{0 . 0 1}<\boldsymbol{p} \leq \mathbf{0 . 0 5}^{* *}$ \\
\hline Small cortical & $57(\mathbf{1 8 . 8})$ & $46(\mathbf{1 8 . 1})$ & $11(\mathbf{2 3 . 4})$ & $\mathrm{NS}$ \\
\hline Large cortical & $51(\mathbf{1 6 . 9})$ & $46(\mathbf{1 8 . 0})$ & $5(\mathbf{1 0 . 6})$ & NS \\
\hline Small white matter & $44(\mathbf{1 4 . 6})$ & $34(\mathbf{1 3 . 4 )}$ & $10(\mathbf{2 1 . 4})$ & NS \\
\hline Large white matter & $6(\mathbf{2 . 0})$ & $6(2.4)$ & $0(\mathbf{0})$ & NS \\
\hline
\end{tabular}


Table 2

(Continued)

\begin{tabular}{|c|c|c|c|c|}
\hline Variable & All study subjects & $\begin{array}{l}\text { Non-Hippocampal } \\
\text { sclerosis subjects }\end{array}$ & $\begin{array}{c}\text { Hippocampal sclerosis } \\
\text { subjects }\end{array}$ & $p$-value \\
\hline Small basal ganglia & $60(\mathbf{1 9 . 8})$ & 49 (19.2) & $11(\mathbf{2 3 . 4})$ & NS \\
\hline Large basal ganglia & $1(\mathbf{0 . 3})$ & $1(\mathbf{0 . 4})$ & $0(\mathbf{0})$ & NS \\
\hline Small brain stem & $13(4.3)$ & $8(3.1)$ & $5(\mathbf{1 0 . 6})$ & NA \\
\hline Large brain stem & $(0.3) 1$ & $1(\mathbf{0 . 4})$ & $0(\mathbf{0})$ & NS \\
\hline Small cerebellum & $53(\mathbf{1 7 . 6})$ & 43 (16.9) & $10(\mathbf{2 1 . 2})$ & NS \\
\hline Large cerebellum & $15(4.9)$ & $12(4.7)$ & $3(6.4)$ & NS \\
\hline Anterior circulation & $121(\mathbf{4 0 . 1})$ & 100 (39.2) & $21(44.7)$ & NS \\
\hline Posterior circulation & 98 (32.5) & $77(\mathbf{3 0 . 2})$ & $21(44.7)$ & NS \\
\hline \multicolumn{5}{|l|}{ Other vascular variables } \\
\hline Cerebral amyloid angiopathy (all six brain regions) & $103(\mathbf{3 4 . 1})$ & $91(35.7)$ & $12(\mathbf{2 5 . 5})$ & NS \\
\hline Atherosclerosis in the circle of Willis ${ }^{\mathrm{v}}$ & $271(\mathbf{9 0 . 0})$ & $223(\mathbf{9 5 . 3})$ & $48(\mathbf{1 0 0})$ & NS \\
\hline Coronary disease $^{\mathrm{vi}}$ & 289 (95.7) & 245 (96.1) & 44 (93.6) & NS \\
\hline \multicolumn{5}{|l|}{ Immunopositivity } \\
\hline \multicolumn{5}{|l|}{ TDP-43 $3^{\text {vii }}$} \\
\hline CA4 & $1(\mathbf{0 . 4})$ & $3(6.4)$ & $4(\mathbf{1 . 3})$ & NA \\
\hline CA3-CA2 & $3(\mathbf{1 . 0})$ & $1(\mathbf{0 . 4})$ & $2(4.3)$ & NA \\
\hline CA1 + Subiculum & 98 (32.5) & $63(\mathbf{2 4 . 7})$ & 35 (74.5) & $<0.001^{*}$ \\
\hline GCL & $68(22.5)$ & $33(\mathbf{1 2 . 9})$ & $35(74.5)$ & $<0.001^{*}$ \\
\hline \multicolumn{5}{|l|}{$\mathrm{p} 62^{\text {viii }}$} \\
\hline CA4-CA1-Subiculum & $173(\mathbf{5 7 . 7})$ & 144 (56.9) & $29(61.7)$ & NS \\
\hline GCL & 99 (33.0) & $62(\mathbf{2 4 . 5})$ & 37 (78.7) & $<0.001^{*}$ \\
\hline \multicolumn{5}{|l|}{ Tau $^{\text {ix }}$} \\
\hline CA4-CA1-Subiculum & 274 (91.3) & $229(\mathbf{9 0 . 5})$ & $45(95.7)$ & NS \\
\hline GCL & $167(\mathbf{5 5 . 7})$ & $125(49.4)$ & $42(\mathbf{8 9 . 4 )}$ & $<0.001^{*}$ \\
\hline
\end{tabular}

NS, no statistical significance. NA, not applicable, $\mathrm{N}$ too low for descriptive statistical analysis. ${ }^{*} p$ - values $<0.001$, strong statistical significance. ${ }^{* *} 0.01<p \leq 0.05$, weak statistical significance.

${ }^{i}$ A standardized neuropathology protocol for neuritic plaque score developed by the Consortium to Establish a Registry for Alzheimer's Disease (CERAD) [14].

${ }^{i i}$ Criteria utilized, previously published $[12,44]$, a staging scheme for neurofibrillary tangles (NFTs) described by Braak and Braak which encloses six stages: no NFTs, Braak stages I/II with NFTs predominantly in entorhinal cortex and closely related areas, stages III/IV with NFTs more abundant in hippocampus and amygdala while extending slightly into association cortex, and stages V/VI with NFTs widely distributed throughout the neocortex and also involving primary motor and sensory areas.

iii The third CDLB guidelines for diagnosis of Lewy- body Dementia with modified criteria. The load of Lewy- related pathology (LRP) was semiquantitatively scored mild, moderate, severe and very severe and followed by the assignment of the type of LRP (none, brainstempredominant, limbic and diffuse neocortical), [43].

${ }^{\text {iv }}$ The diagnosis of capillary amyloid- $\beta$ was determined using Congo red and confirmed by A $\beta$ immunohistochemistry, both analyzed in six brain areas. The severity of capillary $\mathrm{A} \beta$ was graded semi-quantitatively, and the severity of CAA was based on the percentage of affected vessels [41].

${ }^{\mathrm{v}}$ The arteries of circulus Willis were inspected and opened at autopsy, and the degree of atherosclerosis was estimated based upon severity of obstruction in artery. The classification was subdivided into four categories: none, mild, moderate and severe.

${ }^{\mathrm{vi}}$ Left anterior descending, left circumflex and right coronary arteries were dissected at autopsy. The degree of coronary atherosclerosis was estimated by the pathologist, and scored into four categories: none, mild, moderate and severe [42].

${ }^{\text {vii }}$ The presence of TDP-43 immunoreactivity were assessed in the regions CA1 and subiculum, CA2, CA3-CA4 and granular layer of dentate gyrus. TDP-43 immunoreactivity was determined as positive when NCIs seen in the granular cell layer and CA1 + subiculum.

viii 62 immunoreactivity was scored as positive if seen positive NCIs in the granular cell layer of the dentate gyrus [45].

${ }^{\mathrm{ix}}$ Tau immunoreactivity was recorded mainly as neurofibrillary lesions and neuropil threads in the granular cell layer of the dentate gyrus, sectors CA1-CA4 and subiculum.

changes were more common in the left than in the right hemisphere. On both sides, degree of neuronal loss in the CA1 sector was more severe compared to that in the subiculum (more severe changes in the CA1 sector were seen in $88 \%$ of the sections from the right side, and in $84 \%$ of the sections from the left side). Only one subject (1/47) was found to have HS without any other significant neurodegenerative pathology. This subject had severe bilateral neuronal loss in CA1 and subiculum and robust TDP-43 immunopositivity in the granular cell layer of the dentate fascia (Fig. 1).

The majority of the subjects with HS were women (89.4\%), but there was no statistical evidence for an association between HS and sex (Table 2). Overall, the subjects with HS were older at the time 
of death (on average 12 months), even though this difference was not statistically significant $(p>0.05)$ (Table 2). 45 (95.7\%) of the 47 subjects with HS were demented $(p<0.001)$ (Table 2$)$. The CERAD score was weakly associated with HS $(0.01<p \leq 0.05)$, whereas neither Braak stage nor Lewy related pathology showed any association (Table 2). When frequencies of infarcts in different locations were compared in subjects with and without HS, an association was seen with heart infarct, $0.01<p \leq 0.05$ (Table 2).

HS was strongly associated with TDP-43 positive neuronal cytoplasmic inclusions (NCI) in the granular cell layer of fascia dentate, $p<0.001$ (Table 2). A strong association with TDP-43 positive findings in the sectors CA1 and subiculum was also found (Table 2). In the CA1- sectors and subiculum, TDP-43 staining showed some neuronal cytoplasmic inclusions (NCI) and a few neuronal intranuclear inclusions (NII) (in residual neurons). In addition, short dystrophic neurites, neuropil threads, and rarely in some cases, faintly labelled neurofibrillary tanglelike changes were seen. There was variation in the frequencies found among the TDP-43 deposits in CA1 and subiculum in the HS samples. Tau pathology was recorded mainly as neurofibrillary lesions and neuropil threads. Interestingly, HPtau immunopositivity of the granular cell layer was strongly associated with
HS, $p<0.001$ (Table 2). Not surprisingly, the same applied to p62-positive NCI aggregates, $p<0.001$, (Table 2).

As the TDP-43 positivity in the granular cell layer of the hippocampus has been suggested to be an early marker of HS [23], we also analyzed all the variables listed above comparing subjects with immunopositivity of TDP-43 in the granular cell layer and those without this kind of immunopositivity (Table 3 ). These analyses showed a strongly significant association $(p<0.001)$ with dementia, CERAD score, p62 and HPtau positivity in granular cell layer. The following variables showed more modest association $(0.01<p \leq 0.05)$ : age at death, Braak stage, $\alpha$-synuclein pathology and infarcts in the area of posterior circulation.

\section{DISCUSSION}

In this population-based study on subjects $>85$ years old, we found that 1) prevalence of HS was $16 \%$, thus representing one of the most frequent neuropathologies in this age group. 2) Almost a half (49\%) of subjects with HS showed unilateral disease. 3) Only $2 \%$ of subjects with HS did not show any other neurodegenerative pathology, suggesting that HS without any comorbid pathology is rare. 4) HS was strongly associated with dementia, immunopos-

Table 3

TDP-43 immunopositivity in the granular cell layer. Results of association analyses with different variables

\begin{tabular}{|c|c|c|c|c|}
\hline Variable & All study subjects & $\begin{array}{c}\text { TDP-43GCL- } \\
\text { immunonegative subjects }\end{array}$ & $\begin{array}{c}\text { TDP-43GCL- } \\
\text { immunopositive subjects }\end{array}$ & $p$-value \\
\hline Number of subjects & 302 & 234 & 68 & \\
\hline \multicolumn{5}{|l|}{ Gender } \\
\hline Female/Male & $250(\mathbf{8 2 . 8}) / 52(\mathbf{1 7 . 2})$ & $191(\mathbf{8 1 . 6}) / 43(\mathbf{1 8 . 4})$ & $59(86.8) / 9(13.2)$ & NS \\
\hline \multicolumn{5}{|l|}{ Age at death } \\
\hline Mean & 92.35 & 92.09 & 93.23 & $0.01<p \leq \mathbf{0 . 0 5}^{* *}$ \\
\hline Range & $85.12-105.64$ & $85.12-105.64$ & $86.61-103.02$ & \\
\hline \multicolumn{5}{|l|}{ Dementia status } \\
\hline Demented/non-demented & $195(\mathbf{6 4 . 6}) / 107(35.4)$ & $135(57.7) / 99(42.3)$ & $60(\mathbf{8 8 . 2}) / 8(11.8)$ & $<0.001^{*}$ \\
\hline Demented: Female/Male & $165(\mathbf{8 4 . 6}) / 30(\mathbf{1 5 . 4})$ & $112(\mathbf{8 3}) / 23(\mathbf{1 7})$ & $53(\mathbf{8 8 . 3}) / 7(\mathbf{1 1 . 7})$ & NS \\
\hline CERAD $^{\mathrm{i}}$ & & & & $<0.001^{*}$ \\
\hline None & $71(\mathbf{2 3 . 5})$ & $64(27.4)$ & 7 (10.3) & \\
\hline Sparse & $33(\mathbf{1 0 . 9 )}$ & 26(11.1) & $7(\mathbf{1 0 . 3 )}$ & \\
\hline Moderate & $160(\mathbf{5 3 . 0})$ & $124(53.0)$ & $36(52.9)$ & \\
\hline Frequent & $38(\mathbf{1 2 . 6})$ & $20(8.5)$ & $18(26.5)$ & \\
\hline BRAAK $^{\mathrm{ii}}$ & & & & $0.01<p \leq \mathbf{0 . 0 5}^{* *}$ \\
\hline 0 -II & $89(\mathbf{2 9 . 5})$ & $71(\mathbf{3 0 . 3})$ & $18(\mathbf{2 6 . 5})$ & \\
\hline III-IV & $141(46.7)$ & 115 (49.1) & $26(38.2)$ & \\
\hline V-VI & $72(\mathbf{2 3 . 8})$ & $48(\mathbf{2 0 . 5})$ & $24(35.3)$ & \\
\hline$\alpha$ - synuclein ${ }^{\mathrm{iii}}$ & & & & $0.01<\boldsymbol{p} \leq \mathbf{0 . 0 5}^{* *}$ \\
\hline None & $193(\mathbf{6 3 . 9})$ & $155(66.2)$ & $38(55.9)$ & \\
\hline Brain Stem & $8(\mathbf{2 . 6})$ & $5(2.1)$ & $3(4.4)$ & \\
\hline Limbic & $54(17.9)$ & 44 (18.8) & $10(\mathbf{1 4 . 7})$ & \\
\hline Neocortical & 47 (15.6) & $30(\mathbf{1 2 . 8})$ & 17 (25.0) & \\
\hline
\end{tabular}


Table 3

(Continued)

\begin{tabular}{|c|c|c|c|c|}
\hline Variable & All study subjects & $\begin{array}{c}\text { TDP-43GCL- } \\
\text { immunonegative subjects }\end{array}$ & $\begin{array}{c}\text { TDP-43GCL- } \\
\text { immunopositive subjects }\end{array}$ & $p$-value \\
\hline \multicolumn{5}{|l|}{ Infarct (location) } \\
\hline Non-selected & 162 (53.6) & 121 (51.7) & $41(\mathbf{6 0 . 3})$ & NS \\
\hline Heart & 119 (41.2) & 92 (40.7) & 27 (42.9) & NS \\
\hline Small cortical & 57 (18.9) & 42 (17.9) & $15(22.1)$ & NS \\
\hline Large cortical & 51 (16.9) & $45(19.2)$ & $6(8.8)$ & NS \\
\hline Small white matter & $44(14.7)$ & 34 (14.5) & $10(14.7)$ & NS \\
\hline Large white matter & $6(2.0)$ & $4(1.7)$ & $2(2.9)$ & NS \\
\hline Small basal ganglia & $60(19.8)$ & 44 (18.8) & $16(23.5)$ & NS \\
\hline Large basal ganglia & $1(\mathbf{0 . 3})$ & $0(\mathbf{0})$ & $1(\mathbf{1 . 5})$ & NS \\
\hline Small brain stem & $13(\mathbf{4 . 3})$ & $9(\mathbf{3 . 8})$ & $4(5.9)$ & NS \\
\hline Large brain stem & $1(\mathbf{0 . 3 )}$ & $1(\mathbf{0 . 4 )}$ & $0(\mathbf{0})$ & NS \\
\hline Small cerebellum & $53(\mathbf{1 7 . 5})$ & 38 (16.2) & $15(\mathbf{2 2 . 1})$ & NS \\
\hline Large cerebellum & $15(\mathbf{5 . 0})$ & $11(4.7)$ & $4(5.9)$ & NS \\
\hline Anterior circulation & $121(\mathbf{4 0 . 0})$ & 93 (39.7) & $28(41.2)$ & NS \\
\hline Posterior circulation & 98 (32.5) & $69(\mathbf{2 9 . 5 )}$ & 29 (42.6) & $0.01<p \leq 0.05^{* *}$ \\
\hline \multicolumn{5}{|l|}{ Other vascular variables } \\
\hline $\begin{array}{l}\text { Cerebral amyloid angiopathy } \\
\text { (all six brain regions) iv }\end{array}$ & $199(65.9)$ & $148(63.2)$ & $51(68.0)$ & NS \\
\hline Atherosclerosis in the circle of Willis ${ }^{\mathrm{V}}$ & $271(\mathbf{9 0 . 0})$ & $211(\mathbf{9 5 . 5})$ & $60(98.4)$ & NS \\
\hline Coronary disease $^{\mathrm{vi}}$ & $232(\mathbf{8 0 . 3})$ & 178 (78.8) & $54(\mathbf{8 5 . 7})$ & NS \\
\hline \multicolumn{5}{|l|}{$\begin{array}{l}\text { Immunopositivity } \\
\text { p62 }\end{array}$} \\
\hline CA4-CA1-Subiculum & $173(57.7)$ & 134 (57.5) & $39(58.2)$ & NS \\
\hline GCL & 99 (33.0) & $43(\mathbf{1 8 . 5 )}$ & $56(83.6)$ & $<0.001 *$ \\
\hline \multicolumn{5}{|l|}{ Tau $^{\mathrm{ix}}$} \\
\hline CA4-CA1-Subiculum & 274 (91.3) & $211(\mathbf{4 7 . 6 )}$ & 63 (94.0) & NS \\
\hline GCL & $167(55.7)$ & $111(47.6)$ & $56(83.6)$ & $<0.001 *$ \\
\hline
\end{tabular}

NS, no statistical significance. NA, not applicable, $\mathrm{N}$ too low for descriptive statistical analysis. ${ }^{*} p$ - values $<0.001$, strong statistical significance. ${ }^{* *} 0.01<p \leq 0.05$, weak statistical significance.

${ }^{\mathrm{i}}$ A standardized neuropathology protocol for neuritic plaque score developed by the Consortium to Establish a Registry for Alzheimer's Disease (CERAD) [14].

${ }^{i i}$ Criteria utilized, previously published $[12,44]$, a staging scheme for neurofibrillary tangles (NFTs) described by Braak and Braak which encloses six stages: no NFTs, Braak stages I/II with NFTs predominantly in entorhinal cortex and closely related areas, stages III/IV with NFTs more abundant in hippocampus and amygdala while extending slightly into association cortex, and stages V/VI with NFTs widely distributed throughout the neocortex and also involving primary motor and sensory areas.

iii The third CDLB guidelines for diagnosis of Lewy-body Dementia with modified criteria. The load of Lewy-related pathology (LRP) was semiquantitatively scored mild, moderate, severe and very severe and followed by the assignment of the type of LRP (none, brainstempredominant, limbic and diffuse neocortical), [43].

${ }^{\text {iv }}$ The diagnosis of capillary amyloid- $\beta$ was determined using Congo red and confirmed by A $\beta$ immunohistochemistry, both analyzed in six brain areas. The severity of capillary A $\beta$ was graded semi-quantitatively, and the severity of CAA was based on the percentage of affected vessels [41].

${ }^{\mathrm{v}}$ The arteries of circulus Willis were inspected and opened at autopsy, and the degree of atherosclerosis was estimated based upon severity of obstruction in artery. The classification was subdivided into four categories: none, mild, moderate and severe.

${ }^{\mathrm{vi}}$ Left anterior descending, left circumflex and right coronary arteries were dissected at autopsy. The degree of coronary atherosclerosis was estimated by the pathologist, and scored into four categories: none, mild, moderate and severe [42].

${ }^{\text {vii }}$ The presence of TDP-43 immunoreactivity were assessed in the regions CA1 and subiculum, CA2, CA3-CA4 and granular layer of dentate gyrus. TDP-43 immunoreactivity was determined as positive when NCIs were seen in the granular cell layer and CA1 + subiculum.

viiip62 immunoreactivity was scored as positive if seen positive NCIs in the granular cell layer of the dentate gyrus [45].

${ }^{\text {ix }}$ Tau immunoreactivity was recorded mainly as neurofibrillary lesions and neuropil threads in the granular cell layer of the dentate gyrus, sectors CA1-CA4 and subiculum.

itivity for TDP-43 and HPtau in the granular cell layer of the fascia dentate in the hippocampus and modestly with AD-associated neuritic plaques (CERAD score) and vascular pathological variables, most notably heart infarcts.

According to the literature, $10-25 \%$ of individuals older than 85 manifest HS in autopsy samples [4,
$6,7,10,11,29,30,34]$. The frequency of $15.6 \%$ found in our study is in accordance with previous studies on this age group [4, 11, 24, 30,34]. Some of the earlier studies have reported lower frequencies, but these studies may have been influenced by their investigation of younger cohorts $[1,2]$. It is noteworthy that the prevalence of HS has been shown 
to increase in the very elderly, particularly after 95 years [7, 17]. This age group was represented in our study, where the mean age at death for HS subjects was 93.22 years, and the oldest subject was 104.7 years old at the time of death. In addition, awareness of HS has considerably increased during the last ten years, which may have influenced the number of diagnoses of HS, and may have had an impact on the prevalence figures. Our study confirmed the strong association with HS and dementia $(p<0,001)[1,3$, $4,6,9,23,32]$. Only 2 out of 47 subjects with HS were not demented (Table 2) and they both had unilateral HS.

Most of the studies have reported male predominance for HS [11, 24, 30]. This is in contrast to our population-based study, as we found women with HS to be more prevalent (Table 2). The difference may reflect the fact that in our population-based sample of the very elderly, the great majority of study subjects were women, whereas most of the other studies have been based on younger populations and the proportion of males has been much greater. This was also the case in the previous community-based study, where the mean age at death was almost 10 years younger than in our study [30].

HS without comorbid neurodegenerative pathology has been reported to occur in $0.4 \%-5.4 \%$ among the individuals with HS $[1,5,9,30]$. We found only one $(2.1 \%)$ such subject. In this study, HS without any significant comorbid pathology was defined according to the following criteria: Braak stage to be zero and the CERAD score to be one, no neurofibrillary tangles seen with HPtau antibody and no sign of Lewy related pathology with $\alpha$-synuclein antibody. In the previously reported studies the definition for HS without any comorbid pathology has varied to some extent $[1,2]$ allowing generally more relaxed criteria.

The borderline between HS and other diseases, in particular $\mathrm{AD}$, has been problematic. $\mathrm{HS}$ as part of aging pathology has been reported to be found in individuals with both low severity of $\mathrm{AD}$ and high severity of AD pathology [35]. The prevalence of HS pathology has been shown to increase dramatically beyond the age 95 , while the prevalence of AD- type pathology declines in that age group $[7,17]$. These findings might suggest that HS and AD pathologies may occur independently from each other, even though they affect the same part of the hippocampus $[7,8]$. In this study we found only a weak association between HS and CERAD neuritic plaque score, in accordance with previous studies, where the co-occurrence of HS pathology with vari- able CERAD neuritic plaque scores has been reported [35]. More interestingly, we did not find any association with Braak stage, but HPtau-immunopositivity in the granular cell layer was associated with both HS and granular cell TDP-43 pathology. This is in agreement with a recent study, where dentate fascia granule cells NFTs were frequently found in HS cases, independent from Braak stage [23].

Laterality of HS has been reported in a few published studies $[11,30]$. In most studies hippocampus is sampled only from one hemisphere, which is a general approach in neuropathological practice, and thus it is possible that the reported frequencies for HS are underestimated. Here, we found $51.1 \%$ of HS cases to be bilateral. Similar frequencies have been seen in those few other studies, which have sampled hippocampi from both hemispheres [11, 30]. Importantly, it should be routine practice in neuropathological examination to sample both hippocampi, in order to be able to make a reliable diagnosis on demented subjects.

We found a strong association between HS and immunopositivity of TDP-43 in the granular cell layer of the fascia dentate, the CA1 and subiculum (Table 2), in accord with previous studies [18-28]. In order to study, if TDP-43 positivity in the granular cell layer of could be an early marker of HS, as suggested recently [23], we performed association analyses using two different dependent variables: 1) HS defined by the HE finding and 2) TDP43positivity in the granular cell layer. We found very similar results in both analyzes, in accordance with the early marker hypothesis, even though TDP43positivity in the granular cells was clearly not specific for HS. Recently, it has also been suggested that TDP-43 pathology in HS could be a secondary phenomenon reflecting pancerebral arteriolosclerosis $[23,40]$. This finding certainly needs to be replicated by other studies. Although some vascular markers were weakly associated with HS and TDP-43 positivity in the granular cells in our material, we do not have data on brain arteriolosclerosis available in our dataset, and thus this hypothesis could not be assessed here.

There are several strengths and limitations in our study. The Vantaa $85+$ study is prospective and population-based, and thus not influenced by selection bias, commonly affecting epidemiological studies. On the other hand, the study material is relative small in size, which may have resulted in lack of power in association analyses. Even though hippocampi from both sides were investigated, we 
were not able to study the possible segmentality of lesions [46], as the hippocampi samples were collected only at the level of the lateral geniculate body. We managed to use the right side hippocampal PEG- embedded tissue blocks (being PEG-embedded for 14-24 years) for HE- and immunohistochemical stainings, after reprocessing of those blocks into FFPE- blocks, which are easier to handle. To the best of our knowledge, this procedure has not been reported before. This method could be useful for other research groups having historical PEG-embedded material.

\section{ACKNOWLEDGMENTS}

This study was financially supported by Academy of Finland and Helsinki University Central Hospital competitive fund (EVO). We are indebted to Dr. Minna Oinas for providing Lewy body disease database, Johannes Ärje for assistance of the statistical analyses and Dr Suvi Hokkanen for inspiring discussions on the study area.

Authors' disclosures available online (https:// www.j-alz.com/manuscript-disclosures/17-1068r1).

\section{REFERENCES}

[1] Ala TA, Beh GO, Frey 2nd WH (2000) Pure hippocampal sclerosis: A rare cause of dementia mimicking Alzheimer's disease. Neurology 54, 843-848.

[2] Amador-Ortiz C, Ahmed Z, Zehr C, Dickson DW (2007) Hippocampal sclerosis dementia differs from hippocampal sclerosis in frontal lobe degeneration. Acta Neuropathol 113, 245-252.

[3] Corey-Bloom J, Sabbagh MN, Bondi MW, Hansen L, Alford MF, Masliah E, Thal LJ (1997) Hippocampal sclerosis contributes to dementia in the elderly. Neurology $\mathbf{4 8 ,}$ 154-160.

[4] Dickson DW, Davies P, Bevona C, Van Hoeven KH, Factor SM, Grober E, Aronson MK, Crystal HA (1994) Hippocampal sclerosis: A common pathological feature of dementia in very old ( $>$ or $=80$ years of age) humans. Acta Neuropathol 88, 212-221.

[5] Jellinger K (2000) Pure hippocampal sclerosis: A rare cause of dementia mimicking Alzheimer's disease. Neurology 55, 739-740.

[6] Jellinger KA (1994) Hippocampal sclerosis: A common pathological feature of dementia in very old humans. Acta Neuropathol 88, 599.

[7] Nelson PT, Schmitt FA, Lin Y, Abner EL, Jicha GA, Patel E, Thomason PC, Neltner JH, Smith CD, Santacruz KS, Sonnen JA, Poon LW, Gearing M, Green RC, Woodard JL, Van Eldik LJ, Kryscio RJ (2011) Hippocampal sclerosis in advanced age: Clinical and pathological features. Brain 134, 1506-1518.

[8] Nelson PT, Smith CD, Abner EL, Wilfred BJ, Wang WX, Neltner JH, Baker M, Fardo DW, Kryscio RJ, Scheff SW, Jicha GA, Jellinger KA, Van Eldik LJ, Schmitt FA (2013)
Hippocampal sclerosis of aging, a prevalent and highmorbidity brain disease. Acta Neuropathol 126, 161-177.

[9] Probst A, Taylor KI, Tolnay M (2007) Hippocampal sclerosis dementia: A reappraisal. Acta Neuropathol 114, 335-345.

[10] Zarow C, Sitzer TE, Chui HC (2008) Understanding hippocampal sclerosis in the elderly: Epidemiology, characterization, and diagnostic issues. Curr Neurol Neurosci Rep 8, 363-370.

[11] Zarow C, Weiner MW, Ellis WG, Chui HC (2012) Prevalence, laterality, and comorbidity of hippocampal sclerosis in an autopsy sample. Brain Behav 2, 435-442.

[12] Braak H, Braak E (1991) Neuropathological stageing of Alzheimer-related changes. Acta Neuropathol 82, 239-259.

[13] Davidson YS, Raby S, Foulds PG, Robinson A, Thompson JC, Sikkink S, Yusuf I, Amin H, DuPlessis D, Troakes C, AlSarraj S, Sloan C, Esiri MM, Prasher VP, Allsop D, Neary D, Pickering-Brown SM, Snowden JS, Mann DM (2011) TDP43 pathological changes in early onset familial and sporadic Alzheimer's disease, late onset Alzheimer's disease and Down's syndrome: Association with age, hippocampal sclerosis and clinical phenotype. Acta Neuropathol 122, 703-713.

[14] Hyman BT, Phelps CH, Beach TG, Bigio EH, Cairns NJ, Carrillo MC, Dickson DW, Duyckaerts C, Frosch MP, Masliah E, Mirra SS, Nelson PT, Schneider JA, Thal DR, Thies B, Trojanowski JQ, Vinters HV, Montine TJ (2012) National Institute on Aging-Alzheimer's Association guidelines for the neuropathologic assessment of Alzheimer's disease. Alzheimers Dement 8, 1-13.

[15] Murray ME, Cannon A, Graff-Radford NR, Liesinger AM, Rutherford NJ, Ross OA, Duara R, Carrasquillo MM, Rademakers R, Dickson DW (2014) Differential clinicopathologic and genetic features of late-onset amnestic dementias. Acta Neuropathol 128, 411-421.

[16] Murray ME, Graff-Radford NR, Ross OA, Petersen RC, Duara R, Dickson DW (2011) Neuropathologically defined subtypes of Alzheimer's disease with distinct clinical characteristics: A retrospective study. Lancet Neurol 10, 785-796.

[17] Nelson PT, Head E, Schmitt FA, Davis PR, Neltner JH, Jicha GA, Abner EL, Smith CD, Van Eldik LJ, Kryscio RJ, Scheff SW (2011) Alzheimer's disease is not "brain aging": Neuropathological, genetic, and epidemiological human studies. Acta Neuropathol 121, 571-587.

[18] Amador-Ortiz C, Lin WL, Ahmed Z, Personett D, Davies P, Duara R, Graff-Radford NR, Hutton ML, Dickson DW (2007) TDP-43 immunoreactivity in hippocampal sclerosis and Alzheimer's disease. Ann Neurol 61, 435-445.

[19] Dickson DW (2008) TDP-43 immunoreactivity in neurodegenerative disorders: Disease versus mechanism specificity. Acta Neuropathol 115, 147-149.

[20] Hokkanen SRK, Hunter S, Polvikoski TM, Keage HAD, Minett T, Matthews FE, Brayne C, MRC CFAS and CC75C Study Group (2017) Hippocampal sclerosis, hippocampal neuron loss patterns and Tdp-43 in the aged population. Brain Pathol. doi: 10.1111/bpa.12556

[21] McAleese KE, Walker L, Erskine D, Thomas AJ, McKeith IG, Attems J (2017) TDP-43 pathology in Alzheimer's disease, dementia with Lewy bodies and ageing. Brain Pathol 27, 472-479.

[22] Nag S, Yu L, Capuano AW, Wilson RS, Leurgans SE, Bennett DA, Schneider JA (2015) Hippocampal sclerosis and TDP-43 pathology in aging and Alzheimer disease. Ann Neurol 77, 942-952. 
[23] Nelson PT, Trojanowski JQ, Abner EL, Al-Janabi OM, Jicha GA, Schmitt FA, Smith CD, Fardo DW, Wang WX, Kryscio RJ, Neltner JH, Kukull WA, Cykowski MD, Van Eldik LJ, Ighodaro ET (2016) "New Old Pathologies": AD, PART, and Cerebral Age-Related TDP-43 Wih Sclerosis (CARTS). J Neuropathol Exp Neurol 75, 482-498.

[24] Pao WC, Dickson DW, Crook JE, Finch NA, Rademakers R, Graff-Radford NR (2011) Hippocampal sclerosis in the elderly: Genetic and pathologic findings, some mimicking Alzheimer disease clinically. Alzheimer Dis Assoc Disord 25, 364-368.

[25] Rauramaa T, Pikkarainen M, Englund E, Ince PG, Jellinger K, Paetau A, Alafuzoff I (2013) Consensus recommendations on pathologic changes in the hippocampus: A postmortem multicenter inter-rater study. J Neuropathol Exp Neurol 72, 452-461.

[26] Smith VD, Bachstetter AD, Ighodaro E, Roberts K, Abner EL, Fardo DW, Nelson PT (2018) Overlapping but distinct TDP-43 and tau pathologic patterns in aged hippocampi. Brain Pathol 28, 264-273.

[27] Uchino A, Takao M, Hatsuta H, Sumikura H, Nakano Y, Nogami A, Saito Y, Arai T, Nishiyama K, Murayama S (2015) Incidence and extent of TDP-43 accumulation in aging human brain. Acta Neuropathol Commun 3, 35 .

[28] Wilson RS, Yu L, Trojanowski JQ, Chen EY, Boyle PA, Bennett DA, Schneider JA (2013) TDP-43 pathology, cognitive decline, and dementia in old age. JAMA Neurol 70, 1418-1424.

[29] Dutra JR, Cortes EP, Vonsattel JP (2015) Update on hippocampal sclerosis. Curr Neurol Neurosci Rep 15, 67.

[30] Leverenz JB, Agustin CM, Tsuang D, Peskind ER, Edland SD, Nochlin D, DiGiacomo L, Bowen JD, McCormick WC, Teri L, Raskind MA, Kukull WA, Larson EB (2002) Clinical and neuropathological characteristics of hippocampal sclerosis: A community-based study. Arch Neurol 59, 10991106.

[31] Snyder HM, Corriveau RA, Craft S, Faber JE, Greenberg SM, Knopman D, Lamb BT, Montine TJ, Nedergaard M, Schaffer CB, Schneider JA, Wellington C, Wilcock DM, Zipfel GJ, Zlokovic B, Bain LJ, Bosetti F, Galis ZS, Koroshetz W, Carrillo MC (2015) Vascular contributions to cognitive impairment and dementia including Alzheimer's disease. Alzheimers Dement 11, 710-717.

[32] Attems J, Jellinger KA (2006) Hippocampal sclerosis in Alzheimer disease and other dementias. Neurology 66, 775.

[33] Bachstetter AD, Van Eldik LJ, Schmitt FA, Neltner JH, Ighodaro ET, Webster SJ, Patel E, Abner EL, Kryscio RJ, Nelson PT (2015) Disease-related microglia heterogeneity in the hippocampus of Alzheimer's disease, dementia with Lewy bodies, and hippocampal sclerosis of aging. Acta Neuropathol Commun 3, 32.

[34] Barker WW, Luis CA, Kashuba A, Luis M, Harwood DG, Loewenstein D, Waters C, Jimison P, Shepherd E, Sevush S, Graff-Radford N, Newland D, Todd M, Miller B, Gold M, Heilman K, Doty L, Goodman I, Robinson B, Pearl G, Dickson D, Duara R (2002) Relative frequencies of Alzheimer disease, Lewy body, vascular and frontotemporal dementia, and hippocampal sclerosis in the State of Florida Brain Bank. Alzheimer Dis Assoc Disord 16, 203-212.
[35] Brenowitz WD, Monsell SE, Schmitt FA, Kukull WA, Nelson PT (2014) Hippocampal sclerosis of aging is a key Alzheimer's disease mimic: Clinical-pathologic correlations and comparisons with both alzheimer's disease and non-tauopathic frontotemporal lobar degeneration. J Alzheimers Dis 39, 691-702.

[36] Beach TG, Sue L, Scott S, Layne K, Newell A, Walker D, Baker M, Sahara N, Yen SH, Hutton M, Caselli R, Adler C, Connor D, Sabbagh M (2003) Hippocampal sclerosis dementia with tauopathy. Brain Pathol 13, 263-278.

[37] Blass DM, Hatanpaa KJ, Brandt J, Rao V, Steinberg M, Troncoso JC, Rabins PV (2004) Dementia in hippocampal sclerosis resembles frontotemporal dementia more than Alzheimer disease. Neurology 63, 492-497.

[38] Hatanpaa KJ, Raisanen JM, Herndon E, Burns DK, Foong C, Habib AA, White 3rd CL (2014) Hippocampal sclerosis in dementia, epilepsy, and ischemic injury: Differential vulnerability of hippocampal subfields. J Neuropathol Exp Neurol 73, 136-142.

[39] Kovacs GG, Alafuzoff I, Al-Sarraj S, Arzberger T, Bogdanovic N, Capellari S, Ferrer I, Gelpi E, Kovari V, Kretzschmar H, Nagy Z, Parchi P, Seilhean D, Soininen H, Troakes C, Budka H (2008) Mixed brain pathologies in dementia: The BrainNet Europe consortium experience. Dement Geriatr Cogn Disord 26, 343-350.

[40] Neltner JH, Abner EL, Baker S, Schmitt FA, Kryscio RJ, Jicha GA, Smith CD, Hammack E, Kukull WA, Brenowitz WD, Van Eldik LJ, Nelson PT (2014) Arteriolosclerosis that affects multiple brain regions is linked to hippocampal sclerosis of ageing. Brain 137, 255-267.

[41] Makela M, Paetau A, Polvikoski T, Myllykangas L, Tanskanen M (2016) Capillary amyloid-beta protein deposition in a population-based study (Vantaa 85+). J Alzheimers Dis 49, 149-157.

[42] Myllykangas L, Polvikoski T, Sulkava R, Notkola IL, Rastas S, Verkkoniemi A, Tienari PJ, Niinisto L, Hardy J, Perez-Tur J, Kontula K, Haltia M (2001) Association of lipoprotein lipase Ser447Ter polymorphism with brain infarction: A population-based neuropathological study. Ann Med 33, 486-492.

[43] Oinas M, Polvikoski T, Sulkava R, Myllykangas L, Juva K, Notkola IL, Rastas S, Niinisto L, Kalimo H, Paetau A (2009) Neuropathologic findings of dementia with lewy bodies (DLB) in a population-based Vantaa 85+ study. JAlzheimers Dis 18, 677-689.

[44] Polvikoski T, Sulkava R, Myllykangas L, Notkola IL, Niinisto L, Verkkoniemi A, Kainulainen K, Kontula K, Perez-Tur J, Hardy J, Haltia M (2001) Prevalence of Alzheimer's disease in very elderly people: A prospective neuropathological study. Neurology 56, 1690-1696.

[45] Kuusisto E, Kauppinen T, Alafuzoff I (2008) Use of p62/SQSTM1 antibodies for neuropathological diagnosis. Neuropathol Appl Neurobiol 34, 169-180.

[46] Ighodaro ET, Jicha GA, Schmitt FA, Neltner JH, Abner EL, Kryscio RJ, Smith CD, Duplessis T, Anderson S, Patel E, Bachstetter A, Van Eldik LJ, Nelson PT (2015) Hippocampal sclerosis of aging can be segmental: Two cases and review of the literature. J Neuropathol Exp Neurol 74, 642-652. 